\title{
Achieving Financial Sustainability Through Digitalization of the Indian Power Sector: Analysis of Post UDAY Performance of Rajasthan Distribution Companies
}

\author{
Namrata Bhardwaj ${ }^{1 *}$, Dr. Dipti Sharma ${ }^{2}$ \\ ${ }^{I}$ Research Scholar, Malaviya National Institute of Technology Jaipur (Rajasthan, India) \\ Email address:2016rhs9502@mnit.ac.in \\ ${ }^{2}$ Associate Professor, Department of Humanities and Social Sciences, Malaviya National Institute of Technology \\ Jaipur (Rajasthan, India) Email address:dsharma.hum@mnit.ac.in \\ ${ }^{*}$ Corresponding Author: 2016rhs9502@mnit.ac.in
}

\begin{abstract}
Indian power sector is the spine of our economy. However, it is running into continuous losses over the years despite numerous reforms introduced to attain financial sustainability. In 2015 a new financial rescue scheme was implemented specifically to reduce losses of distribution companies (Discoms) known as Ujwal Discom Assurance Yojana (UDAY), which was an optimum mix of technology and adequate funding. The scheme laid down 14 financial and operational parameters on which a Discom's performance was evaluated. While the financial aspect seeks to reduce transmission and distribution losses, elimination of cost-revenue gap, the operational side focused on improving infrastructure \& digitalization via installation of smart meters and feeder metering to enhance collection efficiency and transparency. This paper focuses on the post UDAY performance analysis of Rajasthan Discoms as the three discoms of the State are below average on operational and financial front. This study via survey conducted through structured questionnaire on the officials of Rajasthan Discoms, and data extracted from Ministry of Power and UDAY portal, highlights the progress of distribution utilities under the scheme and gives recommendations to make the sector sustainable in near future with increased digitalization.
\end{abstract}

Keywords: Discoms, UDAY, digitalization, operational \& financial parameters

\section{INTRODUCTION}

Power as we all know is a necessary and a crucial infrastructure for a country's growth and development. Therefore, to attain sustained growth a nation needs to build a strong and financially independent power sector. Indian power sector is one of the most diversified sectors in the world, as power generation sources cover almost all the resources from conventional such as coal, lignite, oil, hydro power, natural gas, nuclear power to nonconventional sources such as solar, wind, domestic and agricultural waste. When we look into the demand side of the power or rather say electricity, it has been noticed that it has increased rapidly and is further expected to take a sharp rise in the near future. To meet this increasing demand, the country needs to add massively to its existing generation capacity. Currently, India stands at third position in terms of producing electricity in the world as per the key world energy statistics published by International Energy Agency. The Government of India is focusing on sustained economic growth by attaining 'Power for all' which in turn has accelerated the capacity addition in the nation. Still poor infrastructure of the Indian power sector continues to remain a major bottleneck for a country's growth and industrialization over the years. Adding to the miseries are the deteriorating financial position of the state utilities. Over the years the state utilities have adopted various reforms to fill the loopholes but they could not succeed due to various reasons. Strained fiscal limitation and lack of digital infrastructure continued to restrict investment in the operation, maintenance and establishment of facilities and considerably burdened the state 
government finances. Year 2003 was marked by landmark "Electricity Act" also known as the Electricity Act of 2003 with an intent to promote competition by opening all the routes of sale and procurement of electricity. Markets emerged which were competitive and therefore, attracted private investments which further changed the institutional structure of the industry by unbundling of the state electricity boards into three segments namely generation, transmission and distribution and in few cases, trading segments. Also, State Electricity Regulatory Commissions (SERCs) were established in each state. Yet again in 2012 the Government of India had to approve new financial rescue scheme for the sector. This bailout amounted to Rs. 1.9 trillion and came in response to financial institutions and banks with large non-performing loans to the power sector. Though the developments in the power sector bought new players into traditionally government ruled sector but they too have been implicated in the crisis. After that there have been various reforms that were initiated for the overall sustainability of the Indian power sector like Electricity Amendment Bill in 2014 which aimed at structural changes in regulatory framework along with Ujwal Discom Assurance Yojana (UDAY) for resolving the financial and operational issues of the power distribution companies. This study deals with the UDAY scheme which was introduced by the Government of India in November, 2015 to ensure the financial sustainability of distribution companies and power sector at large by emphasizing on reducing losses and building digital infrastructure for improved billing and collection efficiency. Beginning from this premise, this paper deals with the structure of the scheme, its objectives and parameters set for performance evaluation of distribution companies. The study further seeks to analyse the performance of Rajasthan's Distribution Companies and the reason behind selecting this particular State for the present research. Subsequently, literature survey and methodology adopted for this research to draw suitable conclusion is presented.

\section{UDAY: FRAMEWORK OF THE FINANCIAL RESCUE SCHEME}

Government of India launched the Ujwal Discom Assurance Yojana in November 2015. This scheme was propagated for the financial turnaround of state distribution companies which were running into huge financial losses. This scheme was proposed with three main objectives:(a) for financial restructuring of Discoms, (b) improving operational efficiency of
Discoms and, (c) reducing the cost of generating power. The scheme anticipates considerable support from state government primarily in the form of (a)taking over $75 \%$ of the Discom debt by the state government which is further divided into two halves i.e. $50 \%$ in FY 2016 and the remaining $25 \%$ in FY 2017; (b) reduction in the rates of interest for the remaining $25 \%$ of the Discom debt, which can be done via issuing Discom bonds backed by the guarantee of state government; (c) the scheme also proposes that states should take over the future losses of Discoms from FY 2016-17 in a graded manner. Further the scheme has laid down fourteen financial and operational parameters on which the performance of each state Discom will be assessed. These parameters include:

- Compulsory metering of feeders and distribution transformers by all the joining states for tracking losses for further immediate action.

- Consumer indexing and Geographic Information System (GIS) mapping of losses to identify the loss incurring areas for strict action.

- Upgradation and installing new meters and transformers in order to minimize technical losses and outages.

- Installing of smart meters above $500 \mathrm{KWh}$ and $200 \mathrm{KWh}$ to reduce electricity theft, improved demand side management, digitalisation and increased consumer engagement.

- Distribution of LED bulbs for better demand side management to reduce peak load and consumption of energy.

- Tariff revisions are required to be done on a quarterly basis in order to counterbalance increase in prices of fuel and to implement this strategy without any chaos.

- Inclusive Information, Education and Communication (IEC) campaign for controlling electricity theft and to amplify participation from public.

- $\quad$ Aggregate technical and commercial (AT\&C) losses to be reduced to $15 \%$ and providing increased supply of power to the states which shows decreasing losses to boost overall financial well-being of Discoms.

- $\quad$ Zero gap between average cost of supply (ACS) and average revenue realized (ARR) to ensure financial sustainability of Discoms. 
Therefore, this scheme seeks to provide a comprehensive framework that is to be followed by the participating states and if followed religiously, this scheme can act as a saviour for the utilities that are currently drowned in debt and are loss making. Next section will deal with the performance analysis of Rajasthan Discoms which bears huge amount of accumulated losses, their progress under the scheme and evaluate how beneficial UDAY proved to be for the Rajasthan state power distribution utilities.

\section{PERFORMANCE ANALYSIS OF RAJASTHAN DISCOMS UNDER UDAY}

Area- wise, Rajasthan is the largest state in India which covers $10.4 \%$ of our country's land area and accounts for $5.7 \%$ (2011 census) of the country's population which contributes around 4.5\% (2014-15) to India's GDP mainly through primary sector. Rajasthan State Electricity Board went into the process of unbundling on 19th July 2000 and was split into (a) Rajasthan Vidyut Utpadan Nigam Limited (RVUNL)- the generation company, (b) Rajasthan Vidyut Prasaran Nigam Limited (RVPNL)- the transmission company and, (c) three distribution companies namely- Jaipur Vidyut Vitran Nigam Limited (JVVNL), Ajmer Vidyut Vitran Nigam Limited (AVVNL) and Jodhpur Vidyut Vitran Nigam Limited (JdVVNL). The generation company of the State operates and owns thermal power stations which are located at Kota and Suratgarh, gas-based power station at Ramgarh, hydel power station at Mahi and mini hydel stations in the State. Though the electricity regulatory authority was established in the State during 2000, tariffs for the State were not revised for the above mentioned three
Discoms during the period 2005-2011 which created a wide gap between the cost of supply and revenue that was being realized. This gap was covered or rather funded by short term loans which created heavy burden on these utilities in the form of outstanding debt. Before the UDAY scheme, in August 2015, the cost coverage ratio remained below unity inspite of three tariff hikes. Also, the AT\&C losses were as high as $27 \%$ for all the three Discoms (Power Finance Corporation Report, 2015). In September 2015, it was reported that the outstanding debt of the Discoms rose to Rs. 80500 crores which was approximately $12 \%$ of the State GSDP (Gross State Domestic Product). UDAY scheme that was launched in the month of November during the same year proposed that the State shall take $75 \%$ of the Discoms outstanding debt in which $50 \%$ of the debt will be taken over in FY 2015-16 and the rest 25\% in FY 2016-17. The scheme also provides for rest of the debt i.e. Rs 20,000 crores to be re-priced or issued as Discom bonds backed up by the State at a $3 \%$ coupon rate lower than the average existing interest rates. Apart from that the scheme lays stress on improving financial and operational efficiency because the 7 th annual integrated ratings on state distribution utilities ranked Discoms of Rajasthan as B graded which clearly emphasized that the Rajasthan Discoms need to work on improving their efficiency parameters. Therefore, the scheme requires all the participating states to reduce their AT\&C losses to $15 \%$ along with eliminating the gap between cost and revenue. Hence, the following section deals with the statistics regarding performance evaluation of State-owned Discoms on the parameters set under the UDAY scheme.

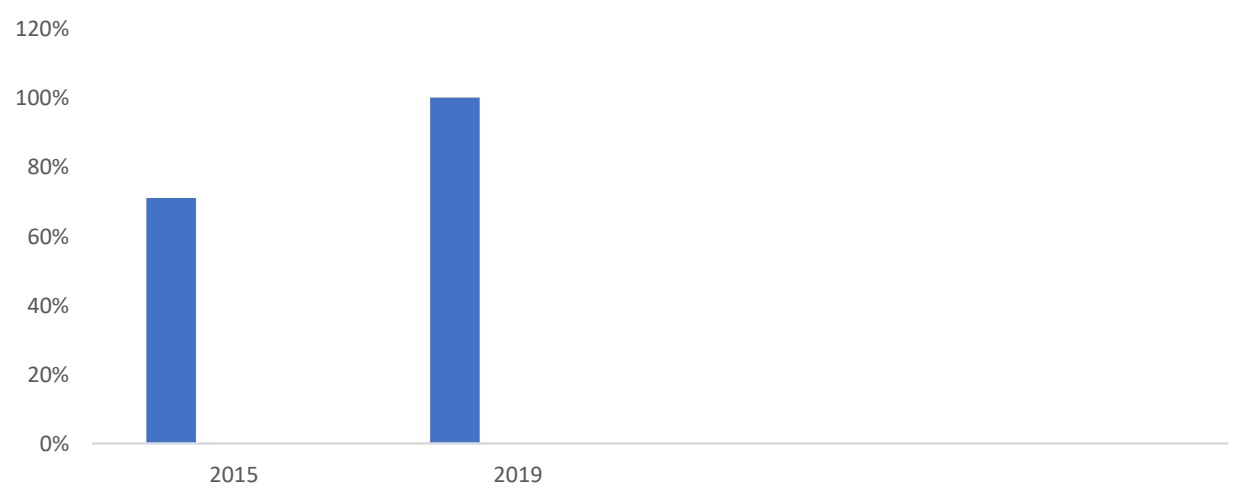

Figure 1: Electrification status in Rajasthan (\% of population) Source: Ministry of Power

The electrification status of Rajasthan state shows improvement from 2015 to 2019 leading it to $100 \%$ electrification which states that each and every household is provided with electricity connection as depicted in Figure 1. 


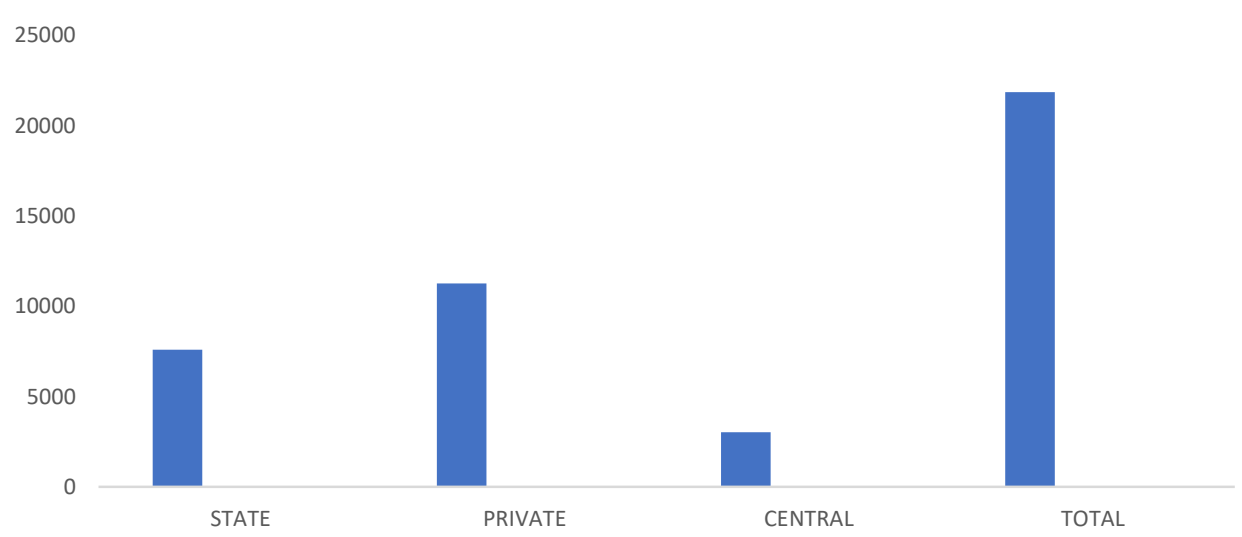

Figure 2: Power generation capacity MW in Rajasthan (2018) Source: Ministry of Power

Figure 2 shows that installed generation capacity of the state is $7574 \mathrm{MW}$, private is $11,242 \mathrm{MW}$ and central is $3017 \mathrm{MW}$ which makes a total generation capacity to $21,833 \mathrm{MW}$.

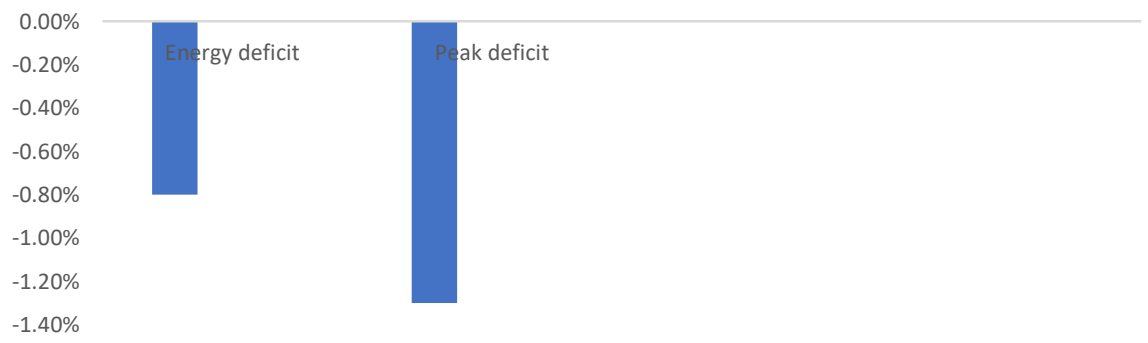

Figure 3: Energy deficit and Peak deficit in Rajasthan (2017-18)

\section{Source: Power Finance Corporation}

Figure 3 shows energy deficit in the State which stands at $-0.8 \%$ and peak deficit at $-1.3 \%$ which is low as compared to other states like Jammu and Kashmir, Andaman \& Nicobar Islands which are

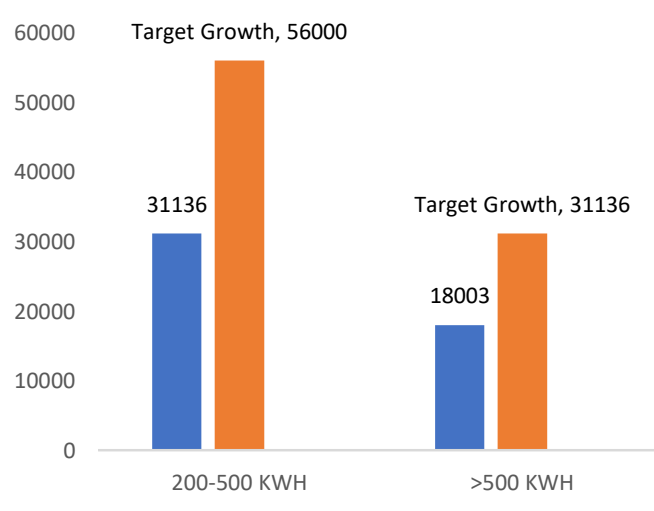

registered to have high energy deficit, still the figures needs to be considered and State should focus on more generation, power purchase and efficient supply of electricity to all the households.

Figure 4: Smart metering in Rajasthan (till 2019) Source: Ministry of Power

Figure 4 reflects on the smart metering process under the UDAY scheme in which the progress till 2019 fails to meet the targeted rate. It was stated that the Discoms should install 56000 smart meters for consumption between $200-500 \mathrm{KWh}$ but the utilities could not meet the required targets as of August 2019. Rajasthan had also set the target to deploy 31136 smart meters for consumers with monthly consumption of over $500 \mathrm{KWh}$ but could only install 18003 meters which is $58 \%$ of its goal 
which shows slow growth on part of the State

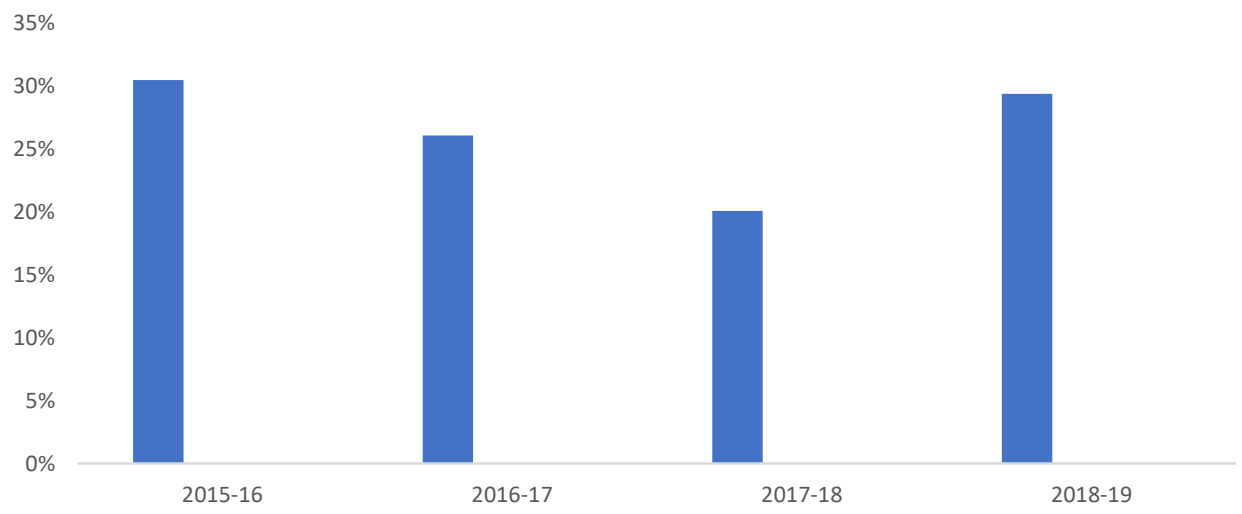

Figure 5: Aggregate Technical \& Commercial Losses of Rajasthan (2015-2019)

\section{Source: Ministry of Power Reports (2015-2019)}

Figure 5 shows the performance of the Discoms on financial parameters viz, AT\&C losses which was targeted to be reduced at $15 \%$ under the UDAY scheme. Though the loss reduction parameter shows a considerable improvement from the year 2015 to

$$
2
$$

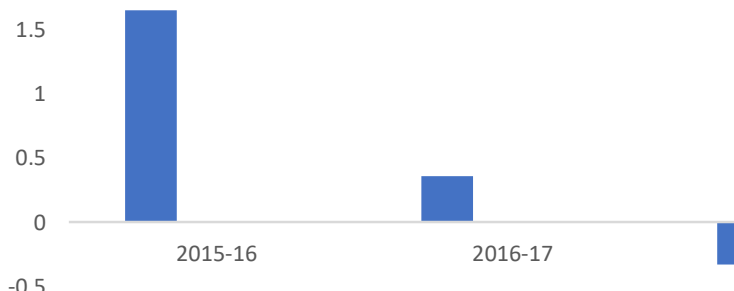

2018 , being reduced from $30.41 \%$ to $20.02 \%$ but again increased to $29.34 \%$ as of September 2019 which clearly states that target has not been achieved and the losses has increased once again in the recent years.

Figure 6: ACS-ARR Gap in Rajasthan (Rs/Unit) Source: Ministry of Power report 2015-2019

Figure 6 shows the gap between average cost of supply and average revenue realized. This parameter has shown improvement over the years decreasing from1.65 Rs/unit in 2015-16 to $0.36 \mathrm{Rs} /$ unit in 201617 and was negative $-0.33 \mathrm{Rs} /$ unit in the year 2017 18 , however it increased to $1.16 \mathrm{Rs} /$ unit in 2018-19 which is far above the set target of zero gap between the two under the UDAY scheme.

\section{LITERATURE REVIEW}

(Mandhir Kumar Verma et.al, 2020) in their study state that it has been almost three decades that India initiated its power sector reforms for improving efficiency and financial viability of the sector but still the sector is suffering from major technical and financial losses that are hindering its growth and sustainability. Authors in their paper analyses the current situation of the sector and factors causing losses to the sector through their comprehensive analysis. It is clearly visible that despite numerous policies, strategies, initiatives and reforms, the distribution side is the weakest link in the Indian power sector. The paper discusses the chronology of reforms and suggests suitable measures that can be implemented at administrative, technical and commercial levels to enhance the quality and reliability of power supply.

(Ajai Nirula, 2019) in the discussion note on assessment of financial and operational sustainability of India's power distribution sector debates about the financial losses of Discoms along with their current and future perspectives. The author further lays stress on the progress made by distribution utilities across the country under the UDAY scheme and observes the disparity between the targeted and achieved growth. The research shows that reduction in AT\&C losses over the years has been slow and erratic. At the same time the progress regarding distribution transformers in both rural and urban 
areas lag behind the target set along with feeder metering which if taken on priority basis can result in proper accounting of subsidised energy supply to the agricultural sector. Hence, a rational strategy that can balance diverse stakeholder interests together with achieving all the targets set by the scheme can lead to the financial sustainability of distribution sector across the country.

(Pinaki Chakraborty et al, 2019) analyses the aggregate situation of Rajasthan's finances by taking power sector into consideration and the recent UDAY scheme. Authors in this paper discusses importance of consolidated funds, presents an overview of state finances, trends in expenditure, UDAY scheme, debt restructuring mechanism of the scheme and post-UDAY long run fiscal trend. By reviewing and analyzing the trends the study seeks to raise questions on the long run sustainability of State debt and deficits, impact of the fiscal responsibility and budget management (FRBM)committee's recommendations on the finances of Government of Rajasthan where debt to GSDP ratio of all states has to be brought down to 20 percent by 2023 . Finally, this study analyses what should be the measurable indicator of fiscal prudence at the state level.

(Kamaljit Singh and Simmi Vashishtha, 2019) presents a study of Haryana state on the launch of UDAY scheme which aims at ensuring efficiency and financial sustainability for the state's power sector. Discoms of Haryana state own a loss of Rs 2374 crore as interest burden on outstanding debt and therefore this study attempts to evaluate the performance of the State distribution utilities on financial and operational parameters. After critically analysing, the authors conclude that performances on operational parameters like DT meter (rural), smart metering above $500 \mathrm{KWH}$ and smart metering between 200 to $500 \mathrm{KWH}$ does not show any significant growth. While on the other side, financial parameters laid under the UDAY scheme reflects that Uttar Haryana Bijli Vitran Nigam Limited has high AT\&C and the gap between ACS and ARR of Dakshin Haryana Bijli Vitran Nigam Limited is significant which is creating a hurdle for the sustainability of the power sector of Haryana.

(Amandeep Kaur and Lekha Chakraborty, 2018) describes the main components and objectives of UDAY scheme in the study and highlight that by 2018, 86 per cent of UDAY bonds had been issued i.e. Rs 2.32 lakh crores out of Rs 2.69 lakh crores, across all states which signed up for the scheme. Their research discloses that most of the states fail to meet their performance on the financial and operational parameters laid down by the scheme. Reviewing data shows that AT\&C losses are $25.41 \%$ as against achieving the stipulated target of $15 \%$ mentioned under the scheme along with significant gap between ACS and ARR. In addition to this the revisions in the tariff structure is still pending in most of the Indian states due to political reasons. Lastly the data on the operational parameters reveals that there is inefficiency on part of power infrastructure and digitisation.

(Atul Agarwal et.al, 2017) analyses the Electricity Amendment Bill of 2014 and the various aspects related to the same. A detailed study of reforms has been undertaken by the author which points out that these reforms started in 1910 and till 1991 they lacked significant structural changes and achievements and the power sector grew at a sluggish rate. The sector went under new reform process every now and then in the form of 1991 reforms or Electricity Act of 2003 but still the sector suffered from losses. In order to deal with distribution sector, it was high time to introduce third generation reforms.

(Siddharth Sareen, 2017) in his study depicts the recent developments and issues in the electricity distribution sector of Rajasthan which has been bailed out for more than $\$ 10$ billion debt by the respective state government in the year 2015. This paper conducts the intensive study of the sector's stakeholders and practices adopted by them, capturing contrasting perspectives which was left unexplored inspite of the adoption of technology, enhancement in efficiency and loss reducing measures that are being implemented. For this purpose, a survey was conducted on thirty experts which further examines the political economy of electricity distribution in Rajasthan. Further the article lays stress on main factors like expectations with respect to recent developments on tariffs, renewable energy and its growth targets, emergence of competition and demand side management.

(Alexander Ryota Keeley and Timothy Dean Keeley, 2016) in their article throws light on the positive side of the financial rescue scheme for the country's distribution companies known as UDAY which was launched in 2015. This paper takes the state of Rajasthan as its case study because it is one of the loss-making utilities and to further illustrate how the financial condition of Discoms are linked to financial status of the states (Ghosh et al., 2017). The study concludes by proposing that the success of the scheme depends upon the cooperation between state and central government and suggests measures to 
improve the financial and operational efficiency of distribution companies.

\section{METHODOLOGY}

The present study uses primary and secondary data in order to arrive at appropriate conclusion. Secondary data is collected from UDAY portal, Government of India and Ministry of Power from 2015-2019. These statistics were used to assess the performance of Rajasthan Discoms under the scheme shown in section 3, and to analyse whether the targets set are fulfilled adequately. At the same time, primary survey was conducted by using stratified random sampling method. The questionnaire was distributed to the officials of the 3 distribution companies of Rajasthan i.e. AVVNL, JVVNL and JdVVNL. The instrument constituted 15 questions based on the 14 financial and operational parameters stated under the scheme targeting to improve the efficiency of the Discoms there by reducing losses, if implemented in the right direction. Sample size for this study was 70 taking into account $10 \%$ of the total population. Out of these, 60 officials responded. Furthermore, the reliability and validity of the questionnaire was tested using Cronbach's alpha formula where the value of alpha came out to be 1.52 which is greater than the alpha value of 0.9 which reflects that the internal consistency of the questionnaire is excellent as per the test's rule of thumb. The formula for Cronbach alpha is:

$\alpha=\frac{N \cdot \bar{c}}{\bar{v}+(N+1) * \bar{c}}$

Where:

$\mathrm{N}=$ number of items

$\bar{c}=$ average covariance between item-pairs

$\bar{v}=$ average variance

The results drawn after analysing the responses of the survey are enumerated in the following section.

\section{RESULTS \& DISCUSSION}

Out of the 60 responses that were received, $33.3 \%$ respondents are from Ajmer Vidyut Vitran Nigam Ltd., $31.7 \%$ are from Jaipur Vidyut Vitran Nigam Ltd. and the remaining 35\% are from Jodhpur Vidyut Vitran Nigam Ltd. Result drawn from the responses are discussed below:

\subsection{Implementation glitches}

\subsubsection{Financial parameters.}

Response analysis on the financial front as depicted in Figure 7 states that $75 \%$ of the respondents agreed to the fact that the scheme has led to reduction in power cuts. $46.7 \%$ claimed that the scheme did not contribute to increased power purchase, $66.7 \%$ believed that dues of the Discoms have not reduced till date, $85 \%$ said that the tariff rates are not revised every three months as per the guidelines and $66.7 \%$ emphasized that the scheme has led to a decrease in the cost of power purchase for Discoms only to an extent and more efforts required in this direction. At the same time $96.7 \%$ of the respondents were of the opinion that high AT\&C losses were a mix of all factors viz; inefficient use of electricity by agricultural consumers; lack in collection efficiency, power theft, unmetered supply and flat tariff. Therefore, the scheme lacks in providing adequate benefits to the State distribution companies on the financial side, however the scheme alone is not responsible as the Discoms shows obtuse pace on implementation of tariffs due to which the gap between cost of supply and revenue realized remain significant. This result in the debt of the Discoms to cover the cost and for further purchase causing financial burden on the companies.

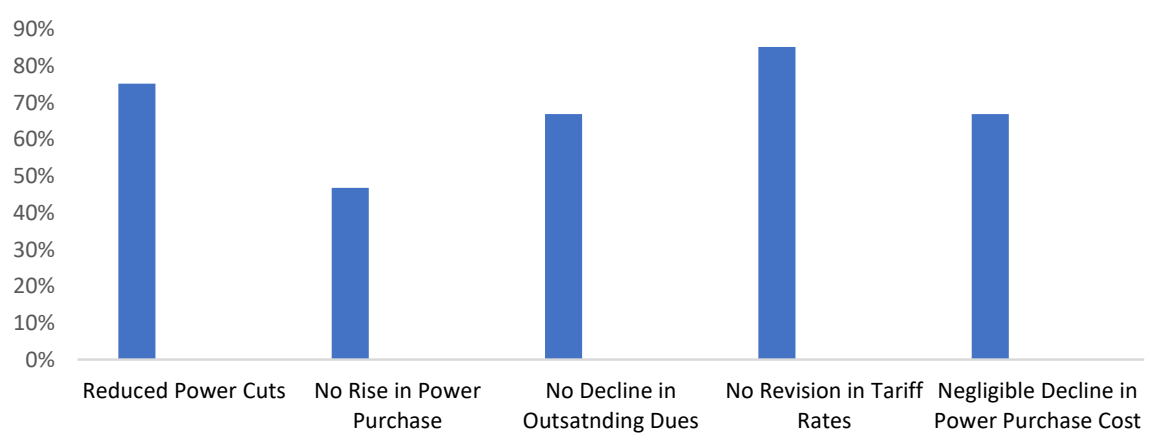

Figure 7: Financial Parameters Impact Source: Survey Questionnaire

6.1.2 Operational parameters: Digitalization and Transparency.
In order to decrease $\mathrm{T} \& \mathrm{D}$ losses and to bring efficiency in the distribution sector the scheme laid 
down certain requisites for the Discoms to build a strong digital infrastructure to fuel the growth of distribution network. Therefore, the progress and contribution of the scheme with regard to the operational parameters like smart metering and feeder metering as per respondents is shown in Figures 8 and $9.88 .3 \%$ of the officials believed that the installation of smart meters has resulted in billing efficiency and $81.7 \%$ agreed to the fact that it has in turn reduced the operation and maintenance cost clearly stating that digital infrastructure has led to enhanced efficiency and reduction in losses. 68.3\% postulates that it has partially rationalised tariff which resulted in flattening of the load curve. 55.5\% believed that this has been able to reduce the transmission losses to some extent however not considerably eliminating them. $78.3 \%$ stated that the work of interstate transmission network is ongoing and if completed on time will result in lowering the cost of power transmission, improving reliability and effectively catering to the nation's future electricity needs. $71.7 \%$ respondents stated that feeder segregation has resulted in improving load management by the Discoms. $86.7 \%$ of the officials agreed to reduction in peak power purchase cost. Majority of the respondents $(88.3 \%)$ stated that digitisation has improved the electricity access to the consumer.63.3\% remarks that UDAY scheme has resulted in increased transparency by purchase of power through competitive bidding. Hence on the operational front this scheme has proved beneficial to some extent and set digitalisation in motion for the sector. However, on the implementation front the stipulated targets have staggered behind in Rajasthan as can be seen from figure 4 where installation of smart metering falls short of the targets. Therefore, these gaps need to be filled to make the scheme successful.

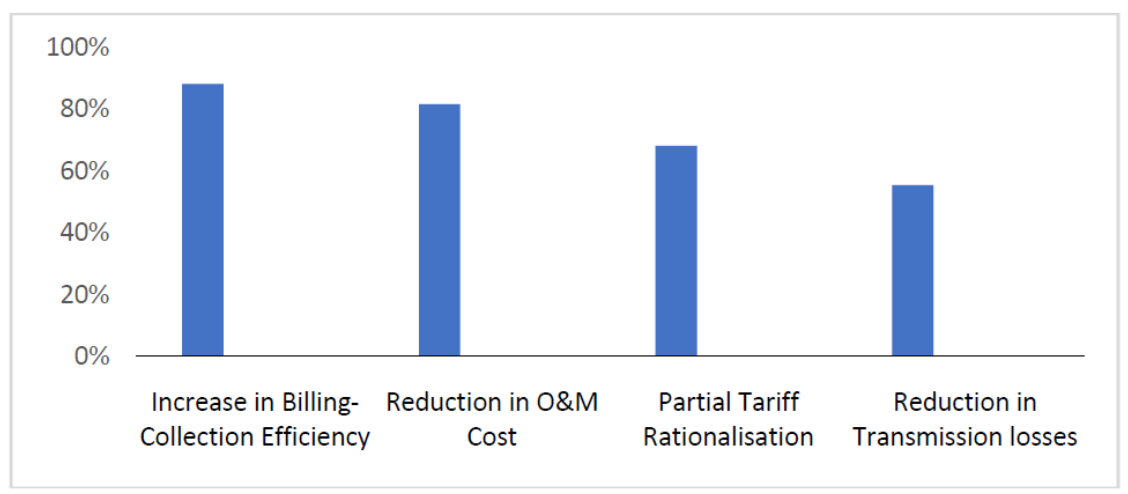

Figure 8: Operational Parameters Impact of Smart Metering Source: Survey Questionnaire

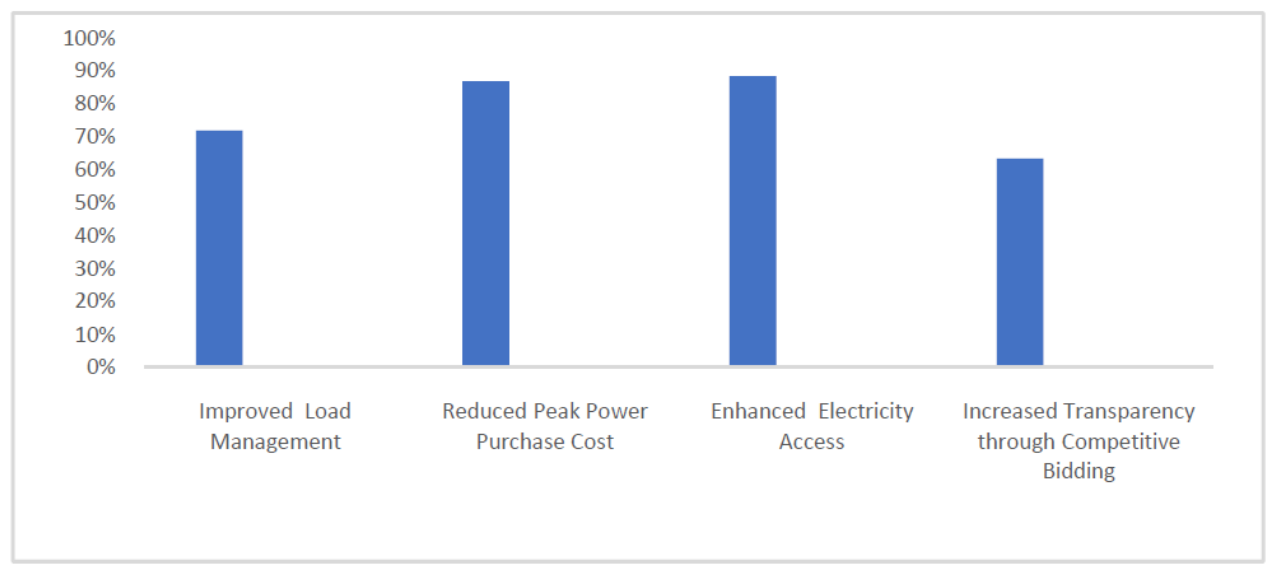

Figure 9: Operational Parameters Impact of Feeder Metering Source: Survey Questionnaire 


\section{CONCLUSION}

The research shows that the Rajasthan state distribution companies are lacking on the implementation part which can be clearly observed from the fact that most of the targets set by the scheme remains truncated and incomplete. Besides, the scheme was unable to fulfil its main agenda to lessen the financial burden of the Discoms and reducing their outstanding dues along with decrease in power purchase cost. Yet, on certain operational parameters like smart metering and feeder metering, digitisation and transparency a pace, although slow, has been set. It is expected that the Government might launch an upgraded version of the scheme, UDAY 2.0 with new targets focusing on achieving greater efficiency via digitalisation and adoption of updated technology to maintain transparency and credibility of the utilities. Therefore, it can be concluded that success of the scheme lies in a joint effort from all the stakeholders i.e. the centre, state, technocrats, regulators and consumers by adopting digital practices, strengthening digital infrastructure for enhanced functioning of the sector along with adopting rational strategy to reduce losses of Discoms and making them financially sustainable across all states.

\section{IMPORTANCE OF THE PRESENT STUDY}

The study undertaken highlights the gap and shortfall of the scheme UDAY along with stressing on the implementation part by the Discoms. Analysis of the current situation of Rajasthan state Discoms, this research recommends filling the loopholes where Government should be more stringent towards the Discoms on timely meeting of targets, while the utilities should contribute towards making this scheme successful by religious implementation of the set goals. The Government is deciding to grant five more years to the Discoms under the scheme for financial turnaround in which the present research can be useful for the state governments and distribution segments to focus on resolving the problem areas and working towards building a financially viable sector.

\section{REFERENCES}

[1] Agrawal, Atul, Anil Kumar, and T. Joji Rao. "Future of Indian power sector reforms: electricity amendment bill " Energy Policy, 107, (2017), 491-497, 2014

[2] Chakraborty, Pinaki, Manish Gupta, and Lekha Chakraborty. "Will UDAY Brighten Up Rajasthan's Finances?" Economic \& Political Weekly ,53.31, (2018): 31 .

[3] Kaur, Amandeep, and Lekha Chakraborty. UDAY Power Debt in Retrospect and Prospects: Analysing the Efficiency Parameters, No. 18/244,(2018).

[4] Keeley, Alexander Ryota, and Timothy Dean Keeley. "Third Financial Bailout for India's State-owned Power Distribution Companies-and Why it Matters." (2016).

[5] Nirula, Ajai. "India's Power Distribution Sector: An assessment of financial and operational sustainability." (2019).

[6] B. Ghosh, C.K. Panigrahi, S. Samanta, Solar Power in Humanitarian Services: Possibilities, IEEE R10 Humanitarian Technology Conference, (2017) 1-5.

[7] Sareen, Siddharth. "Politics, procurement, bailout and buy-in: Woes and ways of Rajasthan's distribution sector."Working Paper, Mapping Power Project Centre for Policy Research and Regulatory Assistance Project, (2017).

[8] Singh, Kamaljit, and SimmiVashishtha. "Empowering the power sector through uday: A study of Haryana." (2019), 1-7.

[9] Verma, Mandhir Kumar, et al. "Indian power distribution sector reforms: A critical review." Energy Policy,144, (2020),111672. 